\title{
PATTERNS OF AUTHORSHIP IN THE BIOMEDICAL LITERATURE OF NIGERIA
}

\author{
Williams E. Nwagwu, PhD \\ Africa Regional Centre for Information Science \\ University of Ibadan, Nigeria \\ Email: willieezi@yahoo.com
}

\begin{abstract}
In this paper, the significance of authorship in biomedical literature is generally described, followed by an empirical illustration using data collected from papers listed in MEDLINE of the National Library of Medicine (USA) on Nigeria. The paper provides an answer to the following question: what is the trend in authorship of biomedical literature on Nigeria since 1967? Addressing this question will contribute to our knowledge of the development and growth of biomedical research and its literature on Nigeria, which in turn is indicative of the productivity of the authors.
\end{abstract}

\section{Keywords: authorship, biomedical literature, Nigeria, co-authorship}

\section{Authorship in Modern Science, an Introduction}

In this paper, the author reviews briefly the significance of authorship in biomedical literature generally and illustrates some aspects of this significance with empirical data drawn from the Nigerian biomedical literature indexed in MEDLINE for the period 19662002. Apart from enhancing the understanding of the structure of authorship of publications in Nigeria's biomedical literature, the paper provides some basis for assessing progress in biomedical research in Nigeria since 1966.

Since the twin debut in 1665 of the earliest known scientific journals, Le Journal des Savans in France, and Philosophical Transactions of the Royal Society in England, the author and the scientific paper have become a standard practice in modern science (Eisenstein, 1979; Gaeta, 1999; Cronin, 2001). Scientists are not only expected to develop knowledge; they are also required to share the knowledge they develop with 
other members of peer communities through formal sources in order to be considered to have contributed to knowledge (Mengxiong, 1993). This expectation is reinforced by certain factors associated with the stratification of knowledge, in which the boundaries of disciplines are sharply differentiated from one another and scientists are expected to promote their disciplines by highlighting their contributions to human well being. There are other factors associated with the institutionalisation of science, in which scientists are required to make contributions to the stock of knowledge in their disciplines in order to be recognized and to rise in the ranks. The contributions of scientists to the solution of society's problems constitute a demonstration of the skills and expertise that scientists bring into the world's knowledge stock and for which they deserve credit. With the increase in competitiveness in the publishing marketplace, however, authorship became tied with reputation, career success, and remuneration, in addition to publication salience and citation. Thus the published paper has become the centerpiece of human intellectual superiority, and every scientist scrambles to sign a paper's byline. Aiyepeku put the reason for this very aptly: "No matter what editors and publishers add to or subtract from manuscripts, the published results remain unequivocally the author's contribution to knowledge" (Aiyepeku, 1976, p. 107). This contribution is, indeed, the bedrock of the significance, momentum, and unprecedented forcefulness with which authorship is presently asserted in modern science.

Historically, authorship evolved from the anonymity of scholarly writings. In her analysis of the early volumes of the Philosophical Transactions, Katzen (1980) notes that

no attempt is made to give prominence to the author of the paper ... there is generally no reference at all to the author in the heading that signals a new communication. If the author is referred to in the title, it is likely to be in an oblique form. (Katzen, 1980, p. 179) 
At the early stages of scientific writing, according to Foucault (1977), scientific texts were accepted on their own merits and positioned within an anonymous and coherent conceptual system of established truths and methods of verification. In his study of seventeenth-century English science, Shapin (1995) observed that authorship used to be asserted with reluctance and that scientific activities were conducted with civility and gentlemanliness in society at large. Whatever a philosopher wrote down was based on what the philosopher saw; philosophers were believed to be upright in writing down their observations. The explanations for this high degree of discreetness could be easily tied to the lack of reward for authorship, financially or otherwise. But with the advent of the institutionalization and the professionalisation of science, authorship became significant, with the standard model based on the assumption that the author is a single person who receives full credit and is held accountable for the claims made in the paper. The appropriation of credit and the allocation of responsibility thus go hand in hand, and this makes for a fairly straightforward social accounting. Hence, the "lone scholar" was a popular figure in scholarly mythology (Brodkey, 1987).

Since the middle of the twentieth century, however, changes in the scientific arena have adjusted the nature and structure of scientific communication practices so that authorship has become almost a collective responsibility (Price, 1963; McDonald, 1995; Kassirer \& Angel, 1995). There is an increasing consciousness that the lone author practice ignores the reality that a great deal of scholarly literature is the product of sociotechnical production and communication networks (Kling \& McKim., 1999), which bring together a mix of resources and actors. Following the observation of an increasing 
number of authors per paper, Price (1963) investigated the publication of papers in the field of chemistry and noted a general qualitative change in authorship. The characteristic evidence that all members of large research teams appended their signatures on any papers resulting from their collaboration marked this change. Based on the evidence before him at that time, Price estimated that by 1980 solo authorship would cease in favour of multiple authorship. Although the dramatic change envisaged by Price did not generally occur, increasing multiple author signatures on published papers is now considered a modern research strategy in many fields.

Although there was evidence of co-authorship in the early nineteenth century, Cronin (2001) has suggested that it was only after World War II that joint authorship became very pervasive. He further suggested that co-authorship could be linked to such major advances in technology as putting a man on the moon, splitting the atom, and so on, projects that typically required enormous levels of funding and complex teams of scientists from different disciplines and institutions. Also, this new model of authorship could be largely attributed to increasing trans-disciplinary, trans-institutional, and transnational collaboration among scientists who are aware that collaboration across national, disciplinary, and sectoral boundaries could lead to path-breaking research outputs.

In many fields, it has become a common practice for more than one author to sign the byline of most papers. Data from the Institute for Scientific Information (ISI) show that the number of papers with one hundred authors each increased from 1 in 1981 to 182 in 1994. Also, the average number of authors per paper in Science Citation Index (SCI) increased from 1.83 in 1955 to 3.9 in 1999. In biomedical literature, this observation is significant.

4

LIBRES ISSN 1058-6768 Volume 17, Issue 1, March 2007 


\section{Significance of Co-authorship in the Literature of Biomedicine}

In the biomedical field, multiple authorship is extensively practiced. The appreciable change in authorship exhibited by the New England Journal of Medicine (NEJM) illustrates this. About a hundred years ago, $98 \%$ of the papers published in NEJM were sole authored; as of 1999, the figure for sole-authored papers was less than $5 \%$ with the mean number of authors per NEJM paper being 6.0 (Constantian, 1999). Also, a study of laboratory investigations reported in the Journal of Neurosurgery between 1945 and 1995 found that the average number of authors per scientific paper rose from 1.89 to 4.6 (King, 2000). Generally, MEDLINE reports higher incidents than SCI and has shown that the average number of authors per paper has risen from 1.8 in 1966 to 4.6 in 1999 (Nwagwu, 2005).

Many explanations have been proffered for the increasing occurrence of coauthorship in biomedicine, and they focus mainly on the complexity of the structure and ethnography of the field. For instance, Cronin (2001) has observed that biomedical research often requires intense socialisation and oral communication and so do all aspects of its organisational structure and value system. Biomedical research often involves a multi-level process of decision-making and cross-examination of decisions, each of which is considered crucial to problem solving. The reliance on expert advice and control is usually strictly observed. As a result, the field is mentor-driven, often involving extensive supervision from superior experts as well as team participation among peers (Arunachallam \& Jinandra, 2000; Cronin, 2001). This is further supported by biomedical research focusing on human lives directly or indirectly, which reinforces the need for extensive supervision and cross-examination of decisions and actions. According to 
Newman (2001), this explains why biomedical scientists work in closed groups, with a single supervisor monitoring a relatively large number of apprentices in different units. Even long after training, medical practice is usually carried out in teams with the team composition often reflecting different levels of expertise and apprenticeship to validate and strengthen the impetus for decision-making. Bozeman's (2003) study, which also showed heavy collaboration in biomedicine, provides some further explanations;

Sometimes people collaborate because they are close. Sometimes they collaborate because they have complementary skills, because they are trying to gain access to specialised equipment, share grant money-or attach themselves to a colleague's scientific reputation. (Bozeman, 2003 p. 18)

It can also be observed that biomedicine is becoming increasingly multidisciplinary, often requiring multi-expert input and interaction. Presently, there is hardly any existing area of knowledge that does not have relevance to the field of biomedicine and that has not contributed to or benefited from knowledge of the field. Because biomedical research can affect human lives, what matters is not the disciplinary origin of the author but the solution the author brings to the problem at hand. In addition, in recent years the World Health Organisation (WHO) has made it a policy to consider the opinions of people from different disciplines to be relevant in solving problems in the health system. This policy could also have contributed to promoting the relationship between biomedicine and other fields. There is hardly a single discipline that has not acquired a biomedical suffix, acknowledging the possibility that any discipline might be of relevance in the solution of human health and related problems. The World Health Organisation has also contributed in advocating co-authorship by their recommendation 
that scientists from other biomedical and non-biomedical fields collaborate with medical personnel in seeking and executing certain categories of health research.

It has also been suggested that biomedical research sometimes contributes to the bloating of the number of authors per paper because of its complex national and international infrastructure. In line with this observation, Katzen suggested that

the massive scale and cost of conducting path-breaking research necessitate resource concentration around a number of major laboratories at which large collaborations are instituted to tackle basic research problems which typically require multi-year funding. (Katzen, 1980, p. 16)

According to Kling and Mckim (2000), biomedical research sometimes requires highly complex, distributed socio-technical ensembles, which bring together several scientists from different disciplinary backgrounds. Furthermore, today we see frequent and gratifying examples of medical scientific research institutions establishing co-operation with areas and institutions outside the medical sector in order to contribute to knowledge about the field. The Danish Committee on Scientific Dishonesty (DCSD, 2004) observed that the development is more common among academically trained scientists with different specialties within the health sector than among other science-based areas outside the biomedical field. In recent years, many professional areas in health have started carrying out research as part of their professional work. This is the case with nurses, laboratory workers, and other groups who traditionally engaged in technical activities. Hence, some categories of workers, previously regarded as technicians and therefore excluded from scientific publishing, are today expected to participate in published research. All areas within the medical profession now contribute to medical literature, and they all demand authorship status for almost every contribution they make. Also, 
representatives from the medical science industry and their agencies as well as members of consultancy companies now take part in biomedical research.

Joint authorship in biomedicine has, however, been seriously criticized. There are many scientists who consider multiple authorship in biomedicine to be unwieldy for serious author accountability. As a result, radical opinions [viewpoints?] exist that question the prestige of authorship and all manifestations of author-ity in biomedicine (Birkerts, 1994), and these explain the predilection for such titles in the field as Death of Literature (Kernan, 1990), What is an Author? (Foucault, 1977), "The Death of the Author” (Barthes, 1997), "Authorship is Dying, Long Live Contributorship” (Smith, 1997). As a result, eschatological and postmodernist proposals that authorship in the sector be retired in favour of contributors and guarantorship abound (King, 2000). Beyond just a mere suggestion, in its editorial cover of Saturday, September 20, 1997, the British Medical Journal published the opinions of 16 contributors who supported Rennie and Flanagin's (1994) suggestion of changing authorship to guarantorship and/or contributorship. There appears, therefore, to be some consensus that multiple authorship actually undermines the assumptions commonly held about the nature and entitlements? of authorship and that "this stresses the tested model of authorship in science." (Latour \& Woolger, 1979, p. 3)

Several studies have shown that co-authorship is responsible for the high prolificacy of biomedical scientists (Zuckerman, 1968; Price, 1965; Newman, 2002), and that this introduces some imbalance in the judgment about productivity of scientists generally. The practice of "gift" authorship is also reported to account for the inflationary increase in the number of authors listed on biomedical papers (Smith, 1994). Bestowal of gift of 
authorship on colleagues who had little or no involvement in the reported research has been blamed for facilitating the publication of many fraudulent papers in recent times (Relman, 1983; Huth, 1986; Rennie \& Flanagin, 1994).

Some observers have noted that co-authorship obstructs intuition in abstracting and indexing services in libraries. Usually, abstractors and indexers create spaces in their indexes for expected publications based on the anticipation of the average number of authors per paper. In the case of biomedical literature, the number of authors is not easily predictable because of the increasing rate of multiple-author identities of papers, thus leading to waste of space and sometimes under-estimation of space. Presently, there is no standard for handling the problems that arise when incoming papers have more authors than the estimated spaces. Cronin (2001) has narrated a series of problems that have been encountered by the National Library of Medicine's (U.S.A.) pegging of the maximum number of authors of any paper to two, which has often led to complaints from co-authors whose names were omitted in an index of papers to which they have made contributions. Issues have also been raised regarding the lack of uniformity in the order of author names in multiple author situations. Many different ways of determining order of authorship exist across disciplines, research groups, and countries.

As a result of the foregoing conditions, co-authorship in the biomedical community is being heavily investigated in most developed countries. Empirical studies have systematically followed developments in this regard, establishing the nature, structure, patterns, and determinants of the practice as well as its merits and demerits. At the national level, the National Institute of Health in the U.S.A initiated a program in 1974 to investigate the dynamics of research communication in biomedicine, using collaboration 
as one of the indices to measure the relationship between biomedicine and other fields of knowledge. At the institutional level, the Worm Community System (WCS) at the University of Illinois, U.S.A., designed to capture the full range of knowledge, formal and informal, of the community of molecular biologists studying the nematode worm $C$. elegans, is one of the many collaboratories conducting investigations on the nature and structure of collaboration in biomedicine. There are also regulations regarding various aspects of co-authorship in many countries. The Biomedical Research Council of the United States, for instance, has developed a five-point guideline defining clearly when a scientist deserves authorship status (www.murdoc.edu.au, July 2002). In addition, local institutions have co-authorship committees, co-authorship policy statements, and other related regulations that ensure that these guidelines are implemented (http://www.hms.harvard.edu/integrity/authorship.html, 02/04/2004). In Nigeria and many other developing countries, the complexities involved in the phenomenon of coauthorship in biomedicine are not common knowledge although the co-authorship practice exists.

\section{The Biomedical Literature of Nigeria and Authorship in Its Literature}

As was the case generally, early biomedical literature on Nigeria was dominated by single authorship. The earliest work on Nigeria was probably the thesis of ex-slave J.A.B Horton, submitted at the University of Edinburgh in 1859. Horton subsequently contributed three monographs from 1866 through 1868. Following these, in $1910 \mathrm{~J}$. Randle contributed what could be regarded as the first biomedical journal paper on Nigeria to the British Medical Journal (Horton, 1859; 1866, 1868; Randle, 1910, cited in 
Akhigbe, 1992). A cursory survey of the British Medical Journal (where Nigeria’s early papers were mainly published at that time) showed that single authorship dominated the biomedical literature scene. Even official government reports such as the Nigerian Medical Reports, which today would bear multiple or corporate authorship, had single authors (Akinfeminwa, 1910).

Akhigbe (1992) and Falaiye (2001) have indicated that the biomedical literature of Nigeria, like biomedical literature elsewhere, is becoming increasingly collaborative. This observation is supported by an indication from MEDLINE, a citation database of the National Library of Medicine (NLM), USA, that while only $20 \%$ or 4 of the 20 papers indexed in it in 1966 were co-authored, this picture contrasts very sharply with the situation in 2002 in which over 77\% of the papers were jointly authored (Nwagwu, 2005). This suggests that the biomedical literature of Nigeria reflects an awareness of current authorship practices. In Nigerian academic circles, there is also some general consciousness about the growing trend in co-authorship and its possible consequences in research management. For instance, the Guidelines for the Promotion of Academic Staff at the University of Ibadan in 2001 provided that co-authored papers be audited to ascertain the degree of participation of the individual authors. In addition, co-authored papers are rated lower than sole-authored papers during staff promotion processes despite the evidence in literature that multiple-authored papers have a higher impact than the sole-authored ones. At the national level, the Nigerian Copyright Act (1990) recognised and made provisions for the management of joint-authored papers and other jointlyowned intellectual properties. Furthermore, one of the functions of the Department of Research and Postgraduate Development of the National University Commission has 
been to promote interaction between university research efforts and those of other research-oriented organisations (National University Commission, 2002), which has significant implications for co-authorship.

Nigeria has about 68 private, mission, and public universities; 29 colleges of education; and 40 polytechnics, most of which are carrying out research in biomedicine and related areas (NUC, 2002). Also, a sufficient number of non-governmental organisations (NGOs), community-based organisations (CBOs), bilateral and multilateral initiatives are carrying out research in various aspects of the national life, including biomedicine. But there is as yet no empirical study that shows the patterns of authorship in the biomedical literature specifically, a gap this paper attempts to fill.

There are perhaps issues here connected with the common knowledge regarding the poor state of the economies of developing countries, particularly those of the subSaharan Africa (except South Africa): their scientific communities are very small, scientific activities very sparse and undeveloped, and motivation for research hardly discernible. As a consequence, science in this region could be considered not a very serious undertaking. Some aspects of international science politics can be identified that contribute to the low visibility of Nigeria's biomedical science. One of those observations is that international citation databases are very selective in indexing the sources from developing countries, while they index almost all of their own sources (Nwagwu, 2005).

With specific regard to the co-ordination and management of biomedical literature in Nigeria, there is a Central Medical Library at Yaba, Lagos, under the supervision of the Federal Ministry of Health, mandated by law to be a repository of biomedical publications (FMOH, 1992). Medical libraries are also in all the medical colleges. There 
are pockets of uncoordinated bibliographic services in some of the institutions, but there is no electronic bibliographic indexing service, whether manual or otherwise, at both the central and institutional levels in Nigeria.

Bibliometric studies are not generally popular in many developing countries (Lemoine, 1996). Available references to bibliometric studies on Nigeria are not only scanty and time-discontinuous, but they also seem to have dwelt mainly on analysis of bibliographies (Aiyepeku, 1973; Toye, 1974, 1975) and bibliometric laws (Aiyepeku, 1976, 1977; Alabi, 1984; Gupta, 1989). Studies on authorship in biomedical literature are relatively non-existent. In this regard, therefore, the study of Nwagwu (2005), which focused on authorship patterns in Nigeria's biomedical literature 1967-2002, could be considered very significant.

In addition to such various aspects of the literature as the characteristics of the journals that publish these papers, the papers themselves, and the authors who write the papers, the question of authorship patterns is also very crucial. It shows us which individual journals, or category of journals, for instance, are contributing most to the dissemination of Nigerian biomedical science. It informs us about the origins and channels of Nigerian biomedical science and also tells us which category of journals dominates in disseminating knowledge about Nigerian biomedical science. The authors in the study, their ranks and institutional affiliation, and their backgrounds help us establish the participation and multidisciplinarity of biomedical research in the country. In addition, these indices enable us to examine the growth of literature, which is also an indicator of the growth of science in Nigeria. 


\section{Data and Methods}

The source of data for this study was MEDLINE of the National Library of Medicine of the U.S.A. From the papers counted, data were collected on the number of authors per paper. This study presents a general picture of the distribution of papers as single-author papers (SAL), multiple-author papers (MAL), and total-authors papers (TAL) authored by single authors (SA), multiple authors (MA), and total authors (TA) as well as the measures of co-authorship, namely, the ratio of authors to papers measured as TA/TAL and collaborative coefficients (CC) (Ajiferuke, Burrel, \& Tague, 1988). For ease of data management, the entire period was subdivided into five periods of five years each. The reference to pattern in this paper is in respect to the proportion of papers written by multiple authors as against that written by single authors. Although a rather broad-based range of issues about authorship is identified, the content in this paper is restricted in this paper by the dimensions of indexing available in MEDLINE. MEDLINE supplies additional data only about the first author and none about the secondary authors except their first names. Use data are also not available. The dynamics of authorship discussed and their implications for biomedical literature could be inferred from the changing authorship indices isolated in this paper.

\section{Results}

Table 1 below shows that out of the total of 6820 papers (TAL) on Nigeria indexed in MEDLINE during 1967-2002, 23\% of the papers (SAL) had single authors (SA) while 77\% (MAL) had multiple authors (MA), with an overall ratio of 3.44 authors per paper and a collaborative coefficient of 0.644 . 
Table 1: Percentage ratio of the totals of SAL and MAL, and SA and MA

\begin{tabular}{|l|l|l|l|l|l|}
\hline Periods & SAL (\%) & MAL (\%) & SA (\%) & MA (\%) & CC \\
\hline $1967-1972$ & 78.27 & 27.93 & 64.75 & 35.25 & 0.026 \\
\hline $1973-1978$ & 25.54 & 74.46 & 12.49 & 87.61 & 0.119 \\
\hline $1979-1984$ & 20.77 & 79.23 & 6.43 & 93.57 & 0.231 \\
\hline $1985-1990$ & 20.08 & 79.92 & 5.64 & 94.36 & 0.380 \\
\hline $1991-1996$ & 18.32 & 81.68 & 4.95 & 95.05 & 0.410 \\
\hline $1997-2002$ & 18.55 & 81.45 & 4.57 & 95.43 & 0.528 \\
\hline TOTAL & 22.89 & 77.11 & 6.68 & 93.32 & 0.644 \\
\hline
\end{tabular}

With respect to the authors, Table 1 shows that, overall, more than $93 \%$ wrote in multiple-author status whereas less than $7 \%$ wrote in single-author status. Specifically, single authors accounted for more than 64\% of the authors during 1967-1972 while MA accounted for only 35.25\%. At the close of the period under study, namely 1997-2002, MA accounted for more than $95 \%$ of the papers while SA was responsible for only $18.55 \%$.

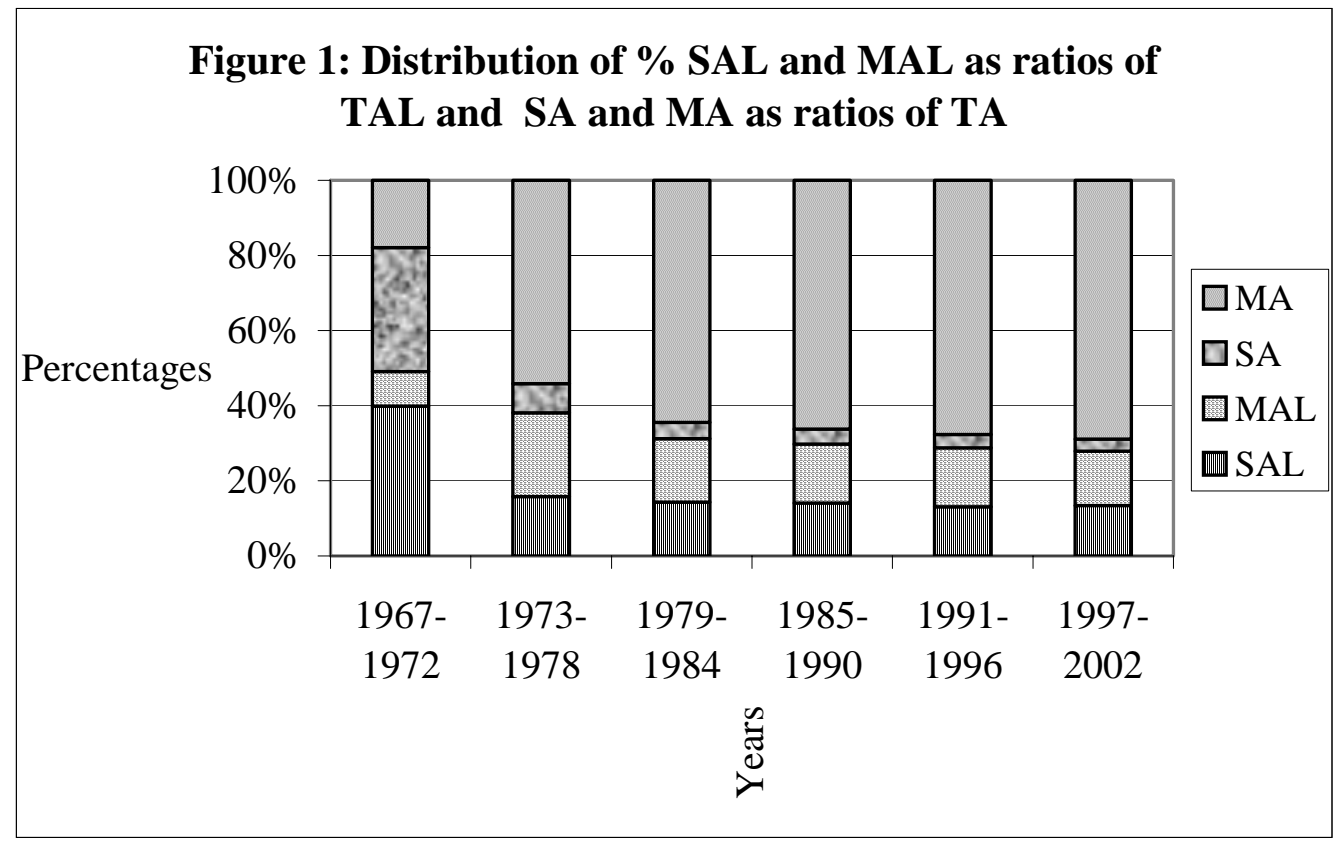


It was necessary to examine thoroughly the pattern of this phenomenon for each of the periods described. The pattern of growth of single (SAL) and multiple author papers (MAL) in relation to total papers (TAL) is shown by comparing the ratios of $\mathrm{SAL} /(\mathrm{SAL}+\mathrm{MAL})$ and $\mathrm{MAL} /(\mathrm{SAL}+\mathrm{MAL})$ for each of the periods. Figure 1 provides an interesting picture of the pattern of authorship. Single-author papers dominated authorship during 1967-1972, after which period SAL dropped and thereafter appeared to maintain a stable growth pattern. Multiple authorship, although in evidence during the previous period, demonstrated its relevance in Nigeria's biomedical literature during the 1973-1978 period, after which the practice tended to remain stagnant in growth. The picture about the authors is somewhat different. Single authors were prominent during 1967-1972, declined drastically during 1973-1978, and then appeared to have remained stagnant during the rest of the periods.

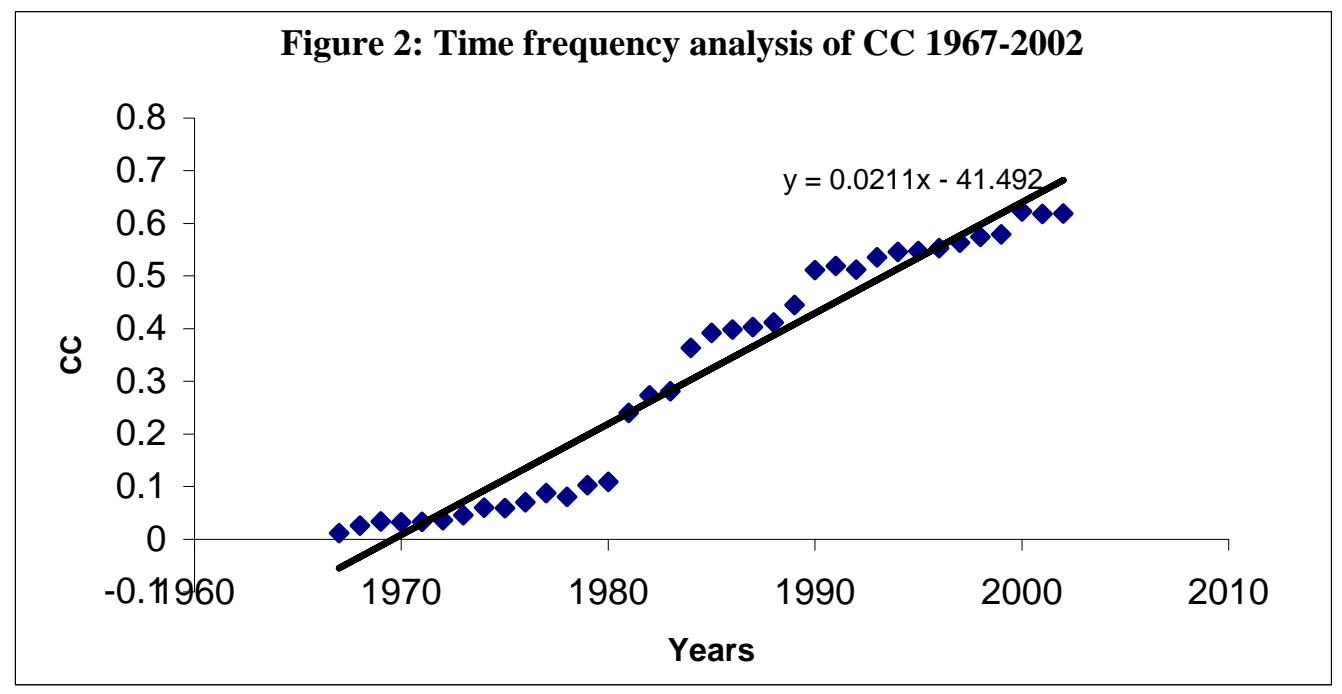

Single-author papers dropped sharply during 1967-1972 and 1973-1978 while multiple authorship increased rapidly, with a point of conflation somewhere between 1967-1972 and 1973-1978 when the decline in SAL coincided with the growth of MAL. 
After this point, SAL dropped gently while MAL increased at nearly the same rate but in the opposite direction. By 1985-1990, however, the rate of growth of multiple- and single-author papers seemed to stabilise somewhat, assuming a nearly straight-line pattern. The pattern of distribution of CC during these periods supports the observation made earlier, namely that multiple authorship picked up very sharply during the first two periods in the study and slowed down thereafter. This is illustrated in the scatter plot in Figure 2.

Authorship of the publications has been examined with respect to whether they were co-authored or not and the authors with respect to whether they wrote the papers in single or multiple statuses. It has been established that co-authorship is an old practice in the biomedical literature of Nigeria, being evident during the 1960s and reaching its peak in the mid 1970s, and that although co-authorship is an old practice in Nigerian biomedical literature, the practice seems to have flattened during the 1979-1984 period, after which it remained relatively stable. Growth in the number of papers also exhibited the same pattern, showing a more rapid growth during 1967-1972 and 1973-1978, then flattening during the periods 1979-1984, 1985-1990, and 1991-1995, and picking up again during the period 1996-2002.

\section{What Is Significant about This Pattern of Authorship of Publications in}

\section{Biomedicine in Nigeria? Discussion and Conclusion}

In order to answer the above question, the results presented in this study will be organized and discussed briefly under three sub-sections as shown below. 


\section{The Circumstance of the Beginning of Formal Biomedical Research in Nigeria}

With independence in 1960, Nigeria set out with what could be considered a very weak starting point in terms of home-based scientific potential (Eisemon \& Davis, 1991), having only one university (at Ibadan, established under the colonial government in 1947). However, various stages of intensive development of research institutes and universities were initiated (in addition to the University of Ibadan) during the 1960s, 1970s, 1980s, and 1990s (Davis, 1983; Gaillard, 1996). Biomedicine, being Nigeria’s first entry point into tertiary education, benefited from this development (Nwagwu, 2005). The nascent democracy of the new independence, however, was truncated in 1966 by a military coup d'etat. The subsequent regime of the military under General Yakubu Gowon (1960-1970) marked the beginning of economic mismanagement and an interruption of the sanctuary model of university administration. One of the factors that could be considered a setback in biomedical scientific development in Nigeria during this period is the civil war of 1967-1970, which disrupted academic activities for about three years. These setbacks notwithstanding, the 1970s constituted a positive landmark in tertiary educational development in Nigeria. There was an enormous increase in the academic population and a steady growth in the number of research scientists (Waast \& Gaillard, 2002), underpinned mainly by aid from various organizations. This took on

diverse forms, including fellowships for training; research grants to individuals and teams; institution building; strengthening and twinning North/South partnership research programmes; and so on (Gaillard, 1996). This is reflected in the pattern of scholarly publications. 
Nigeria's first encounter with modern science and technology was the result of European administration. Many of the scientific pursuits in Nigeria were confined to exploration, surveys, data collection, and the application of techniques, mainly to promote colonial economic policies. Nevertheless, the science that took place during this period left an important legacy in Nigeria in terms of detailed inventories and recorded bodies of knowledge, the creation of specialized research institutes, full-time researchers employed as civil servants, and strategic choices in which agriculture and health, for example, emerged as research priorities. This legacy seemed to grow even stronger after independence. In the 1960s, it was enriched by the development of national higher education systems. In the 1970s, it was bolstered by the "nationalization" of research institutes, the "Nigerianisation" of staff both at research institutes and universities, the expansion and multiplication of institutions, and the creation of national coordinating bodies mandated to define, implement, and monitor national policies. In short, from 1965 to 1985, the Nigerian states put considerable effort into developing national research systems with support from bilateral and multilateral cooperation schemes (Gailliard, 1996). Such widespread trends fostered a mode of scientific development in which the state played a central role. That in turn propelled a new process of scientific production "national science.” The era of national science resulted in some real success stories. In the mid-1980s, Nigerian scientific publications became visible on the international scene, eminent scientific figures emerged, centres of excellence acquired international reputations, and some celebrated innovations originated from homegrown scientific research (Eisemon \& Davis, 1991). Meanwhile, external funding for science and joint research initiatives with universities and research institutes declined due to the 
mismanagement of national wealth and internal and external protests against the repressive policies of the military regimes. Under such circumstances, it should come as no surprise that the best scientific talent continued to leave in large numbers, creating a chronic "brain drain” problem. In addition, during the same period, official development assistance from the world's richest countries stood at $0.22 \%$ of the national gross domestic product, far below the internationally agreed-upon target of $0.7 \%$.

The figures of the number of publications for each of the five periods in this study would suggest a continuous increase in the number of publications during the period under study. The number of publications during 1967-1972 was almost half that for 19731978, just as the figures for 1979-1984 were almost twice those of the previous five-year period. But this trend dropped during 1985-1990, dropping even more during 1991-1996 than in the foregoing period. Although the number of publications picked up again during 1997-2002, the increase was still less than that occurring during the 1967-1972, 19731978, 1979-1984, and 1985-1990 periods. Hence, growth in the number of publications was not consistent throughout the time covered in this study.

The earliest scientific papers in the world date back to 1665 in Europe whereas the earliest references to biomedical research and publications on Nigeria date back only to 1859 in England (Nwagwu, 2005). The establishment of the University College Hospital in Ibadan in 1945 as a campus of the University of London, metamorphosing into the University of Ibadan in 1947, marked the formal beginning of research and higher education in Nigeria. Very significantly too, the establishment of a medical library alongside the medical college marked the institutionalization of biomedical literature in 
Nigeria. Hence, biomedical publications on Nigeria predated the institutionalization of both biomedical research and its literature.

The expectation that researchers build on the work of their predecessors, a privilege the early Nigerian biomedical scientists would not have had, makes these observations very significant and could explain the low volume of biomedical publications at the earliest period in this study. It is in this regard that the research

outcomes of African ex-slaves in England in the middle of the $19^{\text {th }}$ century, which marked crucial reference points in the history of biomedical research on Nigeria (Akhigbe, 1996) are very important landmarks. The late introduction of biomedical research in Nigeria would also mean that the number of scientists who participated in research at the beginning were very few. Furthermore, although biomedical literature was formally institutionalized with the establishment of the University College Hospital in 1947, several writers have observed that the information profession in Nigeria is relatively undeveloped. Specifically, medical as well as other subject librarianship are generally undeveloped in most developing countries.

\section{The Growth of Co-authorship and Publications}

The collaborative coefficient (CC) grew from 0.026 to 0.644 during the 1967-2002 period. With a peak of 0.119 during 1973-1978, CC dropped consistently from 0.101 during 1979-1984 to 0.0809 during $1985-1990$ before rising again from 0.110 during 1991-1996 to 0.128 during 1997-2002. Although Cronin (2001) has suggested that coauthorship is a post World War II event, Ajiferuke (1991) is of the opinion that the globally increasing trend in co-authorship is mainly a 1970s experience. It can be inferred 
from the results of this study that Nigerian biomedical scientists embraced co-authorship relatively early in the history of the practice. It is probable that the rapid rate at which scientists writing on Nigerian biomedicine embraced co-authorship can be attributed to a combination of the resilience of researchers at that time and the conducive relationship between local and external scientists who played significant roles as well as maintained a significant presence in the leadership of research institutions in Nigeria. Furthermore, at an early stage of biomedical research in Nigeria, the environment was favorable for both research and educational activities; there were a few universities, and the government encouraged research by providing required infrastructural and other forms of support to motivate researchers. There were also a very few scholars who benefited immensely from the benevolence of international organisations.

The period 1985-1990 witnessed the onset of an economic crisis marked by structural adjustment programmes initiated by the military regime of General Ibrahim Babangida. In addition, the period marked a high point in the moral and governance crisis arising from the hegemonic policies of the military governments. The social adjustment necessitated by these developments gave rise to a state of anomie manifested in gross under-funding of the universities, institutional breakdown, brain drain, industrial conflicts involving university staff, incessant closures of schools, and irregular university calendars. There was also the desecration of the sacrosanct status of academia to the extent that the military governments solely appointed university officers. Furthermore, the period also marked the beginning of serious conflicts in the universities and other tertiary institutions. The implications of this development on research cannot be overemphasised. While salaries of university workers became much lower than those of their 
counterparts in industry, research and laboratory facilities were also not available. As has been the case in many developing countries, the parallel between governance and research outputs became very prominent. Because the governments had no respect for research as a strategy for generating information that could feed back into the policies of government, researchers seemed to be carrying out research in order be promoted and not necessarily to solve any problems.

\section{The Flattening and Rising of Co-authorship and Publications}

The period 1991-1996 marked the peak of the mass protest to oust the military regime in Nigeria. The height of the political crisis was accentuated by the annulment of the results of the democratically conducted election and the consequent occurrence of what could be considered one of the worst political crises in Nigeria. By 1999, a new civilian regime under Chief Olusegun Obasanjo was inaugurated. The relative peace and freedom in the new government and the introduction of new favourable policies could account for the increase in scientific publications in the field during 1999-2002. During this period, most of the embargoes placed on Nigeria by the various international communities were lifted; foreign aid, most of which had been withdrawn during the period, was restored.

According to Rahman \& Fukui. (2003), the decline in publications in biomedicine since the 1990s is an Africa-wide experience. They showed that all the continents of the world except Africa showed a positive trend, with Africa's share of the total number of publications going down from 1.2 to 0.8 publications per million populations. Perhaps a more crucial observation is that the global pattern of scientific production generally has 
been flattening since 1992. According to the National Science Foundation (NSF) of the United States of America,

The number of S\&E papers by authors based in the United States has remained flat since 1992, even though real $R \& D$ expenditures and the number of researchers continued to rise. This trend diverged from that of most other OECD countries during this period and is a reversal from 3 prior decades of consistent growth. The reasons for this development remain unknown. (NSF, 2002)

This observation is not peculiar to the United States alone. Three mature industrial countries with significant paper outputs-Canada, the United Kingdom, and the Netherlands—also experienced a similar flattening of paper output starting in the latter half of the 1990s. In addition, in most other OECD countries, increases in paper outputs were slower in the second half of the 1990s than in the first half (NSF, 2002).

Publication volume in Nigeria rose again during the period 1997-2002. This could be accounted for by the onset of a new democratic government in June 1999. This new development came along with the lifting of sanctions against Nigeria by various international communities, again giving Nigerian researchers opportunities to compete for places in the global research infrastructure. Access to international research assistance opened up, and university and other researchers were encouraged to pick up their research tools and begin again to carry out research. Perhaps the immediate rise in research evidence can be accounted for by the fact that at its inception, the new government gave researchers a sense of liberty and freedom to embark upon research activities without any interference. The working conditions of university employees were tremendously improved, salaries were increased, and there were promises that the research infrastructures would be rehabilitated. By the end of 2002, there had been some 
evidence of rehabilitation of some universities; the question of infrastructures had received some attention while the number of universities had increased significantly. Although these changes have turned out to be less significant than expected due to the inability of the new democracy to live up to its promises, they show clearly that much of the lag in scientific progress in Nigeria can be linked to an unfavourable social, economic, and political environment.

\section{References}

Aiyepeku, W. O. (1973). Bibliometric and documentation characteristics of geographical literature on Nigeria, 1901-1970. Doctoral dissertation, University of Ibadan.

Aiyepeku, W. O. (1976). The productivity of geographical authors: A case study from Nigeria. Journal of Documentation, 32, 105-117.

Aiyepeku, W. O. (1977). The Bradford's distribution theory: The compounding of Bradford's periodical literatures in geography. Journal of Documentation, 33(3), 210-221.

Ajiferuke, I. S. Y. (1991). A bibliometric model for the distribution of authorships. Journal of American Society for Information Science, 42(4), 279-289.

Ajiferuke, I. S. Y., Burrel, Q., \& Tague, J. (1988). Collaborative coefficient: A single measure of the degrees of co-authorship in research. Scientometrics, 14(5-6), 421433.

Akhigbe, O. O. (1992). Archives, registry, and health literature: The evolutionary process of a national health information system. In Proceedings of the National Conference on Health Information System (draft). Lagos, Nigeria: Federal Ministry of Health,

Akinfemiwa, M. A. (1910). Nigeria's medical reports 1864-1910. Lagos, Nigeria: Federal Ministry of Health.

Alabi, G. A. (1984). Bradford's law and the Nigerian entomological literature. Insect Science and its Applications, 5(7), 18-28.

Arunachjallam, S., \& Jinandra, D. (2000). Mapping international co-authorship in science in Asia through co-authorship analysis. Current Science, 29(5).

Barthes, R. (1977). The death of the author. In R. Barthes (Ed.), Image, music, text. Essays selected and translated by S. Heath. New York: Hill and Wang.

Birkets, S. (1994). The Gutenberg elegies: The fate of reading in an electronic age. New York: Fecette Columbine. 
Bozeman, B. (2003, February). The impact of collaboration on research productivity. Paper presented at the Annual Meeting of the American Association for the Advancement of Science, Denver, Colorado.

Brodkey, L. (1987). Academic writing as social practice. Philadelphia: Temple University Press.

Constantian, M. B. (1999). The Gordian knot of multiple authorship. Plastic and Reconstructive Surgery, 103, 2064-2066.

Cronin, B. (2001). Hyper-authorship: A postmodern perversion or evidence of a structural shift in scholarly communication. Journal of American Society for Information Science, 52(7), 558-569.

Danish Committee on Scientific Dishonesty. (2004). Guidelines concerning authorship. Retrieved November 22, 2004, from http://www.forsk.dk/eng/uvvu/publ/annreport95/chap2.htmr

Davis, C. H. (1983). Admissibility of delegates to international meetings. Journal of the American Society for Information Science, 35(1): 56-56.

Eisemon, T. O., \& Davis, C. H. (1991). Can the quality of scientific training and research in Africa be improved by training? Minerva, 29(1), 122-129.

Eisenstein, E. (1979). The book of nature transformed: Introduction: Problems of periodisation. In The printing press as an agent of change: Communications and cultural transformations in early-modern Europe (Vol. 2). Cambridge: Cambridge University Press.

Falaiye, J. (2001, November). The priorities of biomedical journal publication in Africa. Paper presented at the Conference on Health Information Forum: Workshop 20. Organised by International Network for the Availability of Scientific Publications.

Federal Ministry of Health (FMOH). (1990). University linkage programme. Department of Planning Research and Statistics. Lagos: FMOH.

Federal Ministry of Health (FMOH). (1993). Workplan for health systems research for Nigeria 1993-2000. Lagos: FMOH.

Flanagin, A., Carey, L., Fontanasora, P. B., Phillips, S. G., Pace B. P., Lundberg, G. D., \& Rennie, D. (1998). Prevalence of papers with honorary authors and ghost authors in peer reviewed medical journals. Journal of American Medical Association, 280, 223.

Foucault, M. (1977). What is an author? In D. F. Douchard (Ed.), Language, counter memory, practice: Selected essays and interviews. Ithaca, New York: Cornell University Press.

Gaeta, T. J. (1999). Authorship "law” and order. Academic Emergency Medicine, 6, 297301. 
Gaillard, J. (1996). Science policies and cooperation in Africa. Knowledge, 14(2), 212226.

Gupta, D. K. (1989). Scientometric study of biochemical literature of Nigeria, 1970-1984. Scientometrics, 15(3-4), 171-179 http://www.forsk.dk/eng/uvvu/publ/annreport95/chap2.htmr

Huth, E. J. (1986a). Abuses and uses of authorship [editorial]. Annals of Internal Medicine, 104, 266-267.

Kassirer, J. P., \& Angel, M. (1991). On authorship and acknowledgements. New England Journal of Medicine, 325, 1510-1512.

Katzen, M. F. (1980). The changing appearance of research journals in science and technology: An analysis and a case study. In A. J. Meadows (Ed), Development of scientific publication in Europe. Amsterdam: Elsevier Science Publishers.

Kernan, A. (1990). The death of literature. New Haven, CT: Yale University Press.

King, J. T. (2000). How many neurosurgeons does it take to write a paper? Authorship proliferation in neurosurgical research. Neurosurgery, 47, 435-440.

Kling, R., \& McKim, G. (2000). Not just a matter of times: Field differences in the shaping of electronic media in supporting scientific communication. Journal of American Society for Information Science, 51, 1309.

Latour, B., \& Woolger, S. (1979). Laboratory life: The social construction of scientific facts. Beverly Hills California: Sage.

Lemoine, W. (1992). Productivity patterns of men and women scientists in Venezuela. Scientometrics, 24, 282-294.

McDonald, K. A. (1995). Too many co-authors. Chronicle of Higher Education, 5, A35A36.

Mengxiong, L. (1993). Progress in documentation. The complexities of citation practice: A review of citation studies. Journal of Documentation, 49, 390.

National Science Foundation. (NSF). (2002). Science and engineering indicators. Arlington Va: National Science Board. Retrieved January 2005 from www.nsf.gove.sbe.

National University Commission, (NUC). (2002). 2002 diary. Abuja: NUC.

Nigeria National University Commission, NUC. (2002). Federal universities' allocations, releases, and utilization of Part One Research Grants 1993-1995. Research Bulletin.

Newman, M. E. J. (2002). The structure of scientific collaboration networks. Proceedings of National Academy of Science, USA, 404-409. 
Nigeria Copyright Act. (1990). Laws of the federation of Nigeria. Chapter 68. Part IV, Miscellaneous. Lagos: Federal Ministry of Information.

Nwagwu, W. (2005). Mapping the landscape of biomedical research in Nigeria since 1967-2002. Learned Publishing, 18, 200-211.

Price, D. J. D. (1963). Little science, big science. New York: Columbia University Press.

Price, D. S. (1965). Is technology independent of science? A study in statistical historiography. Technology and Culture, 6, 43.

Rahman, M.\& Fuku, T. (2003). Biomedical publication: Global profile and trend. Public Health, 117(4), 274-80.

Relman, A. S. (1983). Lessons from the Darsee affair. New England Journal of Medicine, 8, 1415-1417.

Rennie, D., \& Flanagin, A. (1994). Authorship! Authorship!: Guests, ghosts, grafters and the two-sided coin. Journal of American Medical Association, 271, 49-471.

Science and its publications 1980-1999. Research Evaluation, 10(3), 185-194.

Shapin, S. (1995). A social history of truth. Chicago, Illinois: University of Chicago Press.

Smith, R. (1994). Authorship is dying, long live contributorship. British Medical Journal, 315(7110), 689.

Toye, B. O. (1974) Bibliometrics of entomological research in Nigeria. Nigerian Journal of Entomology, 16, 133.

Toye B. O. (1975). Some characteristics of the Nigerian entomological literature. Nigerian Journal of Entomology, 1, 175.

Toye, D. K. (1987). Lotka's law and productivity patterns of entomological research in Nigeria for the period 1900-1973. Scientometrics, 12, 33.

Waast, R., \& Gaillard, J. (2002). Science in Africa at the dawn of the $21^{\text {st }}$ century. EU/French Ministry of Foreign Affairs Report. Paris: FFM.

Webster, B. (2000). Polish women in science: A bibliometric analysis of Polish science and its publications 1980-1999. Research Evaluation, 10(3). 185-194.

Zuckerman, H. (1968). The scientific elite-Nobel laureates in the United States. New York: Free Press. 